\title{
LA SUTILEZA DE LO FANTÁSTICO EN LA REALIDAD DE JAIME HERNÁNDEZ A TRAVÉS DEL PERSONAJE DE IZZY (ISABEL ORTIZ RUEBENS)
}

\author{
Ana Merino \\ Universidad de Iowa \\ ana-merino@uiowa.edu
}

Recibido: 31-12-2016

Aceptado: 10-05-2017

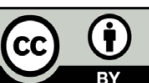

\section{RESUMEN}

Este artículo reflexiona sobre la aparición de elementos fantásticos en las tramas asociadas al personaje de Izzy (Isabel Ortiz Ruebens) del creador de cómic latino Jaime Hernández. Busca destacar la sutileza de lo fantástico y su diálogo con lo verosímil en el complejo espacio del cómic donde palabras y dibujos establecen un pacto narrativo.

Palabras claves: Cómic, lo fantástico, lo metaliterario, ciencia-ficción, ocultismo.

\section{Abstract}

This article reflects on the appearance of fantastic elements in the plots associated with the character of Izzy (Isabel Ortiz Ruebens) in the Works of the Latino comic creator Jaime Hernandez. It seeks to emphasize the subtlety of the fantastic and its dialogue with the plausible in the complex space of the comic, where words and drawings establish a narrative pact..

KeYwords: Comic, fantasy, the metaliterary, science fiction, occultism. 
Jaime Hernández, uno de los autores de cómics más carismático del espacio alternativo estadounidense, co-creador con su hermano Gilbert ${ }^{1}$ de la serie Love and Rockets, es tal vez el que mejor ha retratado la identidad latina urbana y punk que se fue fraguando en la década de los ochenta en la costa oeste de los Estados Unidos. Sus personajes femeninos construyeron discursos afectivos y tramas revolucionarias que normalizaron el sexo lésbico, y abrieron importantes vías para un nuevo feminismo capaz de cuestionar los discursos tradicionales del cómic clásico estadounidense que se caracterizaba por ser blanco, masculino y anglosajón.

El imaginario del universo gráfico-narrativo de las tramas de Jaime Hernández se construye, con un aparente tono realista, alrededor de un lugar llamado Hoppers, un vecindario Mexicano en Huerta, en el estado de California, y que está inspirado en Oxnard, el pueblo donde el autor nació en 1959 y en donde pasó la mayor parte de su infancia y adolescencia. Sin embargo, ese poso realista, está impregnado a su vez de tramas fantásticas que juegan con los lectores y los propios personajes que las experimentan. Jaime Hernández lleva la verosimilitud al límite con guiños metaliterarios y mezclas de géneros. La atmósfera de sus historias, la personalidad de sus protagonistas y el magnífico dibujo de cada viñeta atrapa a unos lectores que asumen todo lo que van viendo con curiosidad y sorpresa. La plasticidad gráfica de los cómics ofrece un doble lenguaje donde las palabras y las imágenes conviven e interactúan en la construcción de las tramas y sus formas de representación.

Isabel María Ortiz Ruebens es uno de los personajes principales en su saga de mujeres «Locas», como las etiqueta el propio Jaime Henández. El personaje de Isabel junto con el de Beatriz García, alias Penny Century, el de Hopey y el de Maggie, formarán parte de un extraordinario elenco de mujeres independientes que renovarán las posibilidades de la ficción literaria en el universo de los cómics americanos. El concepto de la aparente «locura» que las define alude a la forma en la que ellas reivindican su libertad enfrentando el discurso masculino hegemónico que utilizaría la locura como etiqueta para descalificar a la mujer.

El volumen recopilatorio más extenso de las historias de Jaime Hernández fue publicado por la editorial Fantagraphics en 2004 y llevaba como título «LOCAS: The Maggie and Hopey Stories». Esta recopilación ofrecía 704 páginas de historias variadas sobre las chicas de Hoppers que fueron apareciendo en

1. José Manuel Trabado (2014) ha estudiado minuciosamente la fuerza de lo insólito en el trabajo de Gilbert Hernández y su diálogo con el realismo mágico. 
los diferentes volúmenes de cuadernillos de Love and Rockets desde comienzos de los ochenta. Sin embargo se han ido publicando otros libros sueltos antológicos donde se combinan materiales muy variados que no necesariamente coinciden con este grueso volumen de 2004. Su obra es poliédrica, una suma de historias múltiples que construyen un denso, brillante y variado universo propio. Por eso a la hora de profundizar en la obra de Jaime Hernández, es importante utilizar el volumen The Love and Rockets Companion editado por Marc Sobel y Kristy Valenti, aparecido en 2013 para celebrar los treinta años de la serie y que hace recuento minucioso de todas las publicaciones, sus personajes y el contexto en el que aparecen.

La serie Love and Rockets fue un proyecto de los hermanos Jaime y Gilbert, con participaciones esporádicas del hermano mayor Mario. Aunque todas las historias se reuniesen en un mismo cuadernillo seriado que llamaron Love and Rockets, cada hermano desarrolló sus propios personajes, sus propias atmósferas y sus propias tramas dentro de la publicación. En 1981 Gilbert y Jaime se autopublicaron el primer número de Love and Rockets en forma de fanzine. Allí Jaime presenta dos historias: «Mechan-X» $\mathrm{y}$ « How to Kill A... by Isabel Reubens».

Ambas piezas son claves para definir algunos de los rasgos que configuran el universo de sus «Locas» mujeres. La primera pieza de Jaime en el fanzine de 1981 se titula «Mechan-X» y en ella aparece un interesante guiño metaliterario. La viñeta del título presenta a los personajes Maggie, Race y Hopey pero está firmada por Izzy Ruebens y no por Jaime Hernández. Isabel - Izzy - María Ortiz Ruebens es el personaje que representa a la escritora del grupo. La voz apócrifa de Isabel Ortiz se deslizará en diferentes momentos a lo largo de los años de la serie. No será solo un personaje lleno de matices y transformaciones, sino que será consciente de la realidad creadora del cómic mismo en el que participa como autora o personaje en diferentes momentos. En ella Jaime Hernández ha proyectado la voz de un personaje que quiere ser real y trata de explicarnos su mundo literario y la importancia de sus amigas como personajes. Ella hablará a los lectores desde el espacio de su imaginación creadora contándonos las historias de sus amigas. Este personaje a veces aparentará madurez y equilibrio emocional, y otras parecerá que pierde el control de su existencia bordeando la locura visionaria.

En esta primera historia de ocho páginas firmada por Izzy Ruebens descubrimos que Maggie y Hopey son amantes y que Maggie trabaja como mecánica arreglando equipos rotos en una base militar. Esa pequeña base militar tiene un diseño futurista y en ella también trabaja Rand Race, un mecáni- 
co del tipo «prosolar». Maggie se transporta en una especie de moto por propulsión aérea sin ruedas, parecida en su diseño a las acuáticas. Los autos en los que se transportan los mecánicos también serán de propulsión aérea y la trama de esta historia desembocará en un extraño desencuentro en un almacén de robots humanoides. El Jaime Hernández de veinteañero que escribe y dibuja esta historia a comienzos de los ochenta, todavía no sabe bien la dirección que van a tomar sus personajes. Quiere dibujar cómics y está emulando varios estilos en las tramas. La madre de Jaime coleccionaba cómics, y tanto él como sus hermanos fueron lectores voraces de «Los cuatro fantásticos» (de Marvel), «Daniel el travieso», «Archie» o los superhéroes de DC. Jaime ha crecido con dos modelos temáticos en el cómic: la ficción fantástica de los superhéroes, y el de corte realista impregnado de humor cotidiano donde los protagonistas son niños o adolescentes.

La atmosfera futurista de la primera historia de Jaime Hernández conectaba con la tradición del cómic de ciencia-ficción pero su segunda historia «How to Kill A... by Isabel Reubens» está escrita en clave onírica de viñetas mudas. Parece querer jugar con una narración secuencial ensimismada. En la primera viñeta aparece el título en letras blancas gruesas sobre fondo negro sugiriendo una atmósfera misteriosa. Vemos la silueta de una casa construida al borde de un terraplén, y un coche aparcado en la puerta. Una luna llena gigantesca es la que ilumina las siluetas de sombras del coche y la casa. En esta pieza de cuatro páginas observamos al personaje de Isabel Reubens escribiendo a máquina y desesperándose por no lograr escribir una página que le parezca convincente. De pronto, las viñetas nos mostrarán a Isabel saliendo de la casa y yendo con su coche a una especie de cueva donde le espera un hombre de vestimenta extraña que nos recuerda claramente al personaje de Arzach creado por Moebius en 1975 y que representaba lo onírico fantástico de los sueños del autor francés. El sugerente mundo de Arzach había llegado en 1977 a los lectores estadounidenses a través de la revista Heavy Metal y los hermanos Hernández, lectores apasionados de dicha revista, reconocieron en esas viñetas modelos de expresión inspiradores que les ayudaron a entender el potencial liberador de los cómics.

Este hombre que espera a Isabel y nos recuerda al personaje de Moebius, está leyendo una revista titulada True Vatos donde aparece un luchador mexicano con máscara. Jaime Hernández homenajea la ciencia-ficción europea introduciendo los guiños de sus propios códigos chicanos, a la vez que indaga en la textura gráfica de la línea del dibujo y desarrolla la secuencialidad muda. Las escenas que dibuja no necesitan ni bocadillos ni cartelas que 
expliquen las inquietantes cosas que suceden. Isabel beberá de un vaso que le ofrece ese hombre de vestimenta extraña, y se tumba en una mesa de operaciones donde se deja impregnar por el humo que sale de una especie de campana conectada a una maquinaria.

En la siguiente página aparecen seis viñetas mudas con diferentes planos de Isabel enfrentándose a las palabras de su idea literaria. El título «How to Kill A» se apropia de las viñetas y contrasta con los diferentes momentos de Isabel luchando por desarrollar esas ideas. La inspiración, el instante creativo de la mente se representa en seis viñetas donde Isabel está inmersa en diferentes escenografías. Primero de frente con vestido de vuelo y jersey de punto contemplando las hojas blancas de papel por el suelo que tienen letras mayúsculas escritas. En la siguiente viñeta Isabel estará de espaldas al lector, lleva un vestido claro ajustado y es observada por hombres viejos mientras contempla la pared de ladrillo donde aparece un grafiti con su título. En la viñeta de después Isabel aparece caminando con gabardina y botas altas por una calle de ciudad donde las letras de neón de los anuncios construyen el título de su historia. También habrá otra viñeta donde la vemos a 530 pies de profundidad con un bañador de flores rodeada de las palabras de ese título que la obsesiona. Cada viñeta es una exhibición de estilo y diseño. En la quinta viñeta Isabel aparece con vestido chic negro ajustado, guantes, pañuelo y bolso a juego. Sus sandalias de tacón negro han pisado un charco oscuro que va dejando por huellas las letras de su título. En la viñeta que cierra la página, aparece la Isabel escritora desesperada en la cueva, con gesto desesperado y los brazos alzados mientras piensa. Su falda se ha transformado en las letras del título con su nombre deshaciéndose.

Esta página de seis viñetas que representa gráficamente la obsesión creativa de la autora protagonista, en el instante mismo de la invención, hace que el cómic entre dentro de los parámetros de la metaficción. José María Merino al hablar de «Los límites de la ficción» explica que para que un relato entrase «en lo metaliterario, la trama misma, la invención, tiene que tener el propósito de transgredir los límites de la ficción» (2007: 37). La trama de Izzy como autora apócrifa, personaje protagonista y representación gráfica de la historia misma que anhela inventar desde múltiples planos estéticos es un buen ejemplo que transgrede los límites de la ficción. Jaime Hernández juega con las posibilidades mismas de la representación gráfica conceptual de la historia de Izzy, pero lo hace de una forma tan fluida y natural que el lector asume la verosimilitud interna del cómic y su proyección gráfica. Las realidades y planos de Izzy, sus ansiedades, sus miedos, su búsqueda gráfica de la creatividad misma son parte de su lógica interna. 
En la última página Isabel regresa a la máquina de escribir y continua insatisfecha por lo que escribe mientras fuma. La historia se cierra con una viñeta donde se ve la silueta de la casa al borde de un terraplén iluminada por la luz de la luna inmensa que apareció en la primera viñeta. Podríamos pensar que este breve relato a viñetas es sólo un sueño de Isabel, pero con el paso de los años y la publicación de nuevas historias de Jaime Hernández descubriremos que este personaje evocará lo fantástico desde la representación de su cotidianeidad. Izzy se representará como real y reivindicará la realidad que conoce y construye y juega con todas las posibilidades de los relatos que narra.

Gary Groth, propietario junto con el ya fallecido Kim Thompson de la editorial Fantagraphics reconoció, en estas dos historias que aparecen en el primer número del fanzine autopublicado, lo fantástico inquietante que caracterizará algunos aspectos del universo de Jaime. Quedó tan impresionado por estas historias y las de Gilbert Hernández que se ofreció a ser su editor y publicar la serie bajo el sello de Fantagraphics. En el otoño de 1982 aparece el volumen 1 de Love and Rockets publicado bajo el sello de Groth y Thompson. En este volumen se recogen los materiales del fanzine autopublicado más una serie de nuevas historias y episodios que amplían el universo de los hermanos Hernández. En «Locas también» la nueva historia de cuatro páginas que aparece en este primer número editado por Fantagraphics vamos descubriendo que Izzy Ortiz, la escritora del grupo, tiene libros de ocultismo y que le interesa mucho esa temática. Maggie, Hopey y Joey van a su casa para pedirle prestado algunos de sus libros de brujería. La Izzy que aparece en estas viñetas no tiene la misma apariencia que la Isabel Reubens de la otra historia. Ahora la vemos con aspecto gótico, pelo largo y descuidado. Lleva las uñas pintadas de negro y está maquillada de forma tétrica. Izzy se aferra a la pequeña estantería de madera con sus libros de brujería y juega a asustar a sus amigos. Izzy hace que habla con los clavos que sujetan la estructura de la pequeña estantería. Tiene una teoría particular sobre la mala estructura de la estantería y el doble esfuerzo que tienen que hacer los clavos para sujetar las baldas. Izzy personifica a los clavos e imita sus lamentos desesperados pidiendo ayuda:

I can always hear the little nails crying for help! «Help us! Please have mercy! We can't hold on any longer! There's too much pressure! We never did anything bad in our lives! Help! Help! Please! We're going to let go!» Poor Fellows! (2007: 20). 
Los clavos son como los soldados de la costa de un hipotético lugar llamado Zymbodia, condenados a estar siempre listos en un lugar donde no hay guerra y ni se sabe bien lo que hay. Hopey se sonríe porque nota que Izzy hace alusiones a otras realidades usando la metáfora de los clavos condenados a sujetar la madera hasta que se deterioran y son sustituidos por otros nuevos clavos. Hay un matiz de reivindicación política y social que se mezcla con una crítica a lo siniestra que llega a ser la sociedad con los individuos:

and...finally...when they fail to hold the wood any longer...they are shunned... turned away by man...tossed aside...to be replaced by young up-starts...no longer a part of society...friend today, foe tomorrow... (2007: 20).

Maggie se irrita con Izzy por inventar historias que considera absurdas. No entiende la forma metafórica de Izzy de interpretar las cosas y jugar con elementos cotidianas e insignificantes. Maggie e Izzy terminan gritándose la una a la otra, y Maggie se irá furiosas de la casa junto con Hopey y Joey. Hopey le recordará el momento en el que una Izzy con un aspecto más convencional las presentó dos años atrás. Parece que en un par de años Izzy se ha transformado en otra persona convirtiéndose en una especie de bruja licántropa que asusta a sus antiguos amigos.

La serialización y la fragmentación de la trama de los personajes en diferentes historias, nos obliga reconstruir el personaje de Isabel (Izzy) Reubens Ortiz desde varios parámetros. En el volumen 4 aparecido en el otoño de 1983 la página introductoria titulada «Locas también con Maggie, Hopey and Gang» y que sirve de preámbulo a una historia larga en varias partes titulada «100 rooms», tiene un juego metaliterario. Hay una viñeta en la que vemos a Izzy vestida de monja fumando mientras nos dice que ella conoce a Maggie desde que nació y que está en este cómic para contar su historia:

So there you have it. Isn't Maggie the perfect comic book character with her imperfections and her exciting career? Who am I you say? My name is Isabel Ortiz Reubens. I grew up caring for Maggie since she was born. So I'm put in this comic book to tell her story. Isn't that perfect? (2007: 113).

Sin embargo los lectores también querrán saber lo que esconde el personaje de la propia Isabel (Izzy) Ortiz. En el número 7 que aparece en el verano de 1984 Jaime Hernández publicará una historia de cuatro páginas titulada «Locos», en el que Speedy, el hermano de Izzy, le cuenta a su amigo detalles de la vida de su hermana. En ese momento Izzy tiene el aspecto descuidado y 
el propio Speedy la define como una muerto viviente: "You mean besides looking like night of the living dead» (2004: 171). Pero ese aspecto tétrico está ligado a lo que el propio Speedy define como "punker,weirdo voodoo shit» (2004: 172). Su hermana es una especie de bruja moderna que ha construido su propio mito. Perteneció a la banda de «Las Viudas» (Las Widows) cuando era adolescente, a los dieciocho pasó por la cárcel y coindice allí con el grupo mexicanoamericano de las «southside chucas», al salir de la cárcel se centra en los estudios, termina secundaria y va a la universidad. Allí se da cuenta de que quiere ser una escritora de libros de misterio y comienza a enfrentarse con su padre porque la presiona para que se haga maestra de escuela. Speedy y su amigo hacen conjeturas sobre el germen de la extraña inadaptación de Izzy. El amigo se pregunta si fue la amistad de Izzy con Maggie y la punkie Hopey lo que desencadenó el comportamiento extremo. Pero Speedy piensa que ella enloquece cuando se casa con Jack Ruebens, su profesor de inglés de la universidad, un hombre blanco que la dobla la edad. Un año después ya se habían divorciado de su profesor, se había aislado de todos y había dejado de escribir sus piezas de misterio. La Izzy escritora que surge tras su divorcio comienza a escribir sobre temas escabrosos que su hermano apenas entiende: «She started writing about shit like...dead babies and dancing skeletons» (2004: 173). Utilizó el nombre de casada de Isabel Ruebens y le publicaron algunas de esas piezas. Luego se fue a México y todos pensaron que no volvería, pero Izzy le mandó una postal a su madre Juana Ortiz en la que le dice que regresará a casa cuando se libre de ese ser repulsivo, aludiendo a su padre. Y efectivamente, Izzy regresó de México y apareció en el velatorio de su padre con un aspecto demacrado, vestida como una borracha. ¿Qué pasaría en México? El misterio de aquel episodio se proyectará en un relato fantástico que fue publicado en el volumen 29 de Love and Rockets de marzo de 1989. Pero Speedy que nunca sabrá lo que ocurrió, piensa que en México está el germen de esa conducta trastornada de su hermana que le hace caminar por el barrio y asustar al vecindario: «It's like, she's una vampira or something, you know?» (2004: 174). La reflexión descriptiva que Speedy hace del comportamiento errático de su hermana está marcada por una cierta compasión. El reconoce que siente pena por ella. La relación entre estos dos hermanos tendrá su momento más intenso y poético al final de la historia titulada «La muerte de Speedy» que fue a apareciendo en tres partes, en los volúmenes 21, 22 y 23 de Love and Rockets, a lo largo de 1987. La historia que narra los último días de Speedy Ortíz habla de enfrentamiento entre bandas latinas, y relaciones amorosas cruzadas y está escrita en clave realista. La tensión y el sentimiento de 
culpa que sufre Speedy Ortiz le hará cometer una locura, y será al parecer la policía la que lo encuentre en su coche poco antes del amanecer. Sin embargo, en las últimas cinco viñetas de esta historia veremos la silueta de Speedy despertando a su hermana Izzy para decirle que todo va a estar bien y que no se tiene que preocupar por él. Izzy y Speedy han tenido una fuerte discusión el día anterior, y Speedy ha vuelto a la casa porque quiere hacer las paces y tranquilizarla. Izzy medio dormida y desorientada le dice a su hermano que espere un segundo que abra las cortinas, es entonces cuando descubrimos en un plano general el salón de Izzy Ortiz que solamente está ella en la habitación. Jaime Hernández ha jugado con la ambigüedad de las escenas para llevar a los lectores al espacio inquietante de lo fantástico transformando a Speedy en un espectro. La policía ha encontrado el coche de Speedy Ortiz en el arcén poco antes del amanecer. La escena en tres viñetas no nos dice mucho, sólo que los dos policías se sorprenden de lo que encuentran en el coche de Speedy. Así queda la secuencia de la penúltima página. Luego la última página estará marcada por las viñetas en las que el espectro de Speedy se va apareciendo a algunos de los personajes de la historia, para terminar visitando a su hermana.

Antonio Risco considera la literatura fantástica «como aquella en la que lo extranatural se enfrenta con lo natural produciendo una perturbación mental, de cierto orden, en algunos personajes que viven la experiencia y, en cierto término, en el lector» (1987: 139). La historia de «La muerte de Speedy» tuvo un gran impacto entre los lectores por ese final extranatural en el que Speedy se transforma en un espectro que necesita despedirse de las personas que ha herido con su comportamiento. Ese plano fantástico que convive con lo realista contemporáneo tiene su mejor expresión en el personaje de Isabel y el mundo que le rodea. Speedy, que ha sido un personaje inmerso en la realidad y que ha ido definiendo a su hermana y sus excentricidades desde la mirada objetiva realista, se transforma con su muerte en un espectro que arrastra a los lectores al plano de los fantástico cotidiano.

Mucha de la coreografía de los personajes que deambulan por el universo de Jaime Hernández está ligada a guiños fantásticos que de pronto se apropian de la trama. Derek Parker Royal al analizar la obra de Jaime Hernández explica como sus comics suelen construirse en escenarios realistas que representarían la experiencia punk de la costa oeste de las primeras historias de los ochenta y noventa, al ambiente mundano de este presente ahora que los personajes están alcanzando la madurez. Sin embargo Royal también reconoce ese giro fantástico que enriquece las historias: 
At the same time, there is a fantastic side of Jaime's work that occasionally takes center stage. This can be seen, for example, in his earlier «Mechanics» stories where dinosaurs and rocket ships co-exist in a contemporary reality, and in his more recent comics following the superhero antics of Angel Rivera (a Young and athletic friend of Maggie's) and Penny Century (2013: 12).

Gary Groth en una entrevista para The Comics Journal de enero de 1989 aludía a la curiosa relación que Jaime Hernández tenía entonces con lo fantástico y cómo el realismo parecía apropiarse de sus nuevas tramas. Las historias de «Mechanics» que aparecieron en 1983 ofrecían un fuerte componente fantástico en la trama y el ambiente que rodeaba al personaje de Maggie. En esta historia narrada a través de grandes cartelas que funcionan como los textos de las cartas de Maggie a su amiga Hopey, vamos descubriendo las aventuras de Maggie en la villa de Zhato junto a la jungla, arreglando la nave Saturn Stilletto con sus otros colegas mecánicos prosolares. En esta jungla los dinosaurios no se habrán extinguido, y un mundo de ambiente exótico y primitivo se mezclará con la realidad de los mecánicos tratando de arreglar la nave mientras se dedican a jugar al beisbol en su tiempo libre. Curiosamente, lo que a Jaime Hernández le interesaba desarrollar en aquella historia no era lo fantástico sino representar la capacidad de Maggie de relacionarse con su realidad, y así se lo explica a Gary Groth en la entrevista:

what I liked was more how Maggie reacted toward it. Sometimes Maggie worried that they were going to be wiped off the island and be killed and sometimes she just wanted to drink beer. It wasn't so much fantasy stuff that I was having fun with, it was more how people were reacting-playing baseball and over the dinosaur was a home run, stuff like that. And that's what people didn't understand (1989: 36).

Efectivamente los lectores se sentían atraídos e intrigados por las aventuras de Maggie, la mecánica prosolar pero sentían que ese mundo era demasiado ajeno a las aventuras punks de las otras amigas que vivían cerca de Los Ángeles en la realidad de los ochenta. Gary Groth piensa que la línea realista se adueña de la trama porque a Jaime Hernández deja de interesarle dibujar los elementos fantásticos que aparecen en «Mechanics»: «And I think that was because you wanted to tell more realistic stories and you were dissatisfied with "Mechanics", is that it?» $(1989,36)$. Pero Jaime le explicará a Groth en 1989 que era más un problema de verosimilitud y que esos elementos, aunque le encantase dibujarlos, no encajaban: 
it was getting in the way. (...) The more I tried to tell more believable stories, you will still wouldn't believe it if there was a dinosaur or a rocket ship in the background. I still love drawing the stuff, but it doesn't fit (1989: 36).

La realidad punk de los ochenta es la escenografía más novedosa y atractiva que marca el ambiente de estos cómics. A la vez que leemos sobre las aventuras de Maggie trabajando como mecánica en unas tierras de junglas exóticas y llenas de dinosaurios, veremos al final de «Mechanics Part 5» un inciso de una página titulado «Meanwhile...back at the Ranch with Hopey, Izzy and Daffy» donde están las tres amigas conversando sobre los viajes de Maggie y su regreso inminente mientras Izzy le está haciendo un tatuaje casero a Hopey en la mano (2007:60). Según Hopey, todo lo que Maggie narra en sus cartas son exageraciones. A Maggie le gusta dar un toque misterioso y terrorífico a las cosas que cuenta. Incluso Hopey tiene una anécdota en la que recuerda que Maggie les contó cómo, cuando era niña, una noche un hombre loco quiso entrar en la casa para matarla a ella y a toda su familia. Pero resultó que esa historia era una exageración porque según explica Hopey, en realidad ese hombre terrorífico y sanguinario, era un borracho tratando de beber unos tragos cerca de la ventana de la habitación de Maggie. Esta página está firmada en la esquina inferior de la derecha de su última viñeta como «JAIME85» y si vamos al cuadernillo original de 1983 «Love and Rockets. n.2» no la encontraremos. Veremos que en el original el final de la quinta parte de Mechanics termina con la carta de Maggie que relata el día 39 de su expedición donde Tse Tse, la guía e intérprete de los mecánicos en la jungla de Zhato, le cuenta historias terroríficas por la noche mientras contemplan la lluvia incesante. En el pueblo de donde ella viene hay un fantasma llamado «Damacher», que significa la viuda que camina. A veces también lo llaman la Cucuy y al parecer camina por las noches por las calles buscando sus huesos y viste toda de negro. Maggie se asusta y le pide a Tse Tse que deje de contarle esas historias, pero Tse Tse continúa describiendo a la Cucuy: «And her hair and skin be snow white! And her hair goes all over the place! And her eyes go pop pop out her cheeks!..» (1983: 32). Maggie no puede resistirlo y le pide que pare mientras se tapa los oídos y se acurruca. En la siguiente viñeta vemos que Tse Tse continúa con la terrorífica descripción: «Her teeth are green and big like a tiger! And her fingers be long and red! And...» (1983: 32), mientras detrás de la intérprete se dibuja el rostro espeluznante de la viuda con pelo blanco revuelto, dientes afilados, ojos fuera de sus orbitas y manos alargadas y huesudas. Maggie tratará de esconderse debajo de las sábanas mientras Tse Tse in- 
terpreta al fantasma de Cucuy «la viuda que camina» y continúa con su historia. La pobre viuda que camina entrará en los bares preguntado por sus huesos y todos le dirán que no los han visto. Luego llamará a las puertas preguntando por sus huesos, y todos le dirán que no los han visto, y ella llorará desesperada, lanzando gritos por las calles toda la noche imitando la voz de un bebé.

Tse Tse y Maggie se asustarán cuando de repente entre en la habitación, mojada por la lluvia, el personaje de la luchadora Rena Titañón amiga de ambas. Por un momento han creído ver a la viuda que camina. Al final Maggie, como una niña asustada, dormirá entre Rena y Tse Tse. Las historias de fantasmas del pueblo de Tse Tse le han desvelado.

Jaime Hernández estaba construyendo la trama existencial de varios personajes y usaba muchos referentes narrativos de forma intuitiva. Maggie era una mecánica prosolar viajera que escribía cartas a su amiga Hopey y en ellas le contaba aventuras sorprendentes que combinaba con divertidas anécdotas sobre su vida diaria. Describía lugares míticos y exóticos llenos de elementos maravillosos que mezclaban la fantasía con la ciencia-ficción, a la vez narraba sus sentimientos cotidianos y las rutinas del trabajo con sus colegas mecánicos. Mientras tanto sus amigas seguían en California inmersas en la cultura juvenil del punk y las drogas sicodélicas del momento.

Juan Herrero Cecilia en su estudio sobre Estética y pragmática del relato fantástico explica cómo la aparente diferencia entre el género fantástico y el género de la ciencia ficción es fácil de trazar porque ambos géneros están en dos campos bien distintos:

lo fantástico conecta y contrapone el mundo de la vida ordinaria con el mundo de la vida irracional, lo suprarracional y los sobrenatural; mientras que la ciencia ficción explota o extrapola al máximo los resultados o las consecuencias del poder de la razón y de la ciencia inventando un mundo imaginario (una historia de ficción) que podría ser real en un futuro más o menos lejano (2000: 79).

Esta aproximación teórica funcionaría con relatos cerrados, pero en el caso de Jaime Hernández nos encontramos multi-relatos seriados de cómics abiertos de personajes que evolucionan con los años. Hay por lo tanto una hibridez de géneros que juegan con el lector y su capacidad para digerir todas las realidades que presenta. Es cierto que a lo largo de los años las historias de estas mujeres se alejan del genero de la ciencia-ficción y el propio Jaime reconstruye esas tramas como un guiño hiper-fantasioso de Maggie o de la propia Izzy escritora que narra lo que Maggie contaba, y la celebra como personaje. 
En el cuadernillo Love and Rockets número 29 de 1989 Jaime Hernández contará la historia de Isabel en México. Han pasado ocho años desde aquella primera historia con Isabel Ruebens tratando de escribir una historia. Volvemos al mismo paisaje en la primera viñeta: la casa junto al terrible iluminada por la inmensa luna llena. Aquí no está un coche aparcado en la puerta, pero en la segunda viñeta aparece una Isabel escribiendo frenética vestida exactamente igual que en la historia de 1981. Es la Isabel de apariencia serena de pelo corto, camisa blanca, chaleco negro y falda a cuadros sentada frente a la máquina de escribir. En la primera página de seis viñetas mudas descubrimos una suma de acontecimientos vertiginosos. La ruptura de su matrimonio, un aborto, el enfrentamiento con su padre, la desesperación y un intento de suicidio cortándose las venas. Con esta página de imágenes introductoria entramos en una segunda página de viñeta única que da título a la historia: «Flies on the ceiling: The Story of Isabel in Mexico» Esta vez aparece clara la firma del autor como Xaime y la fecha de los años de ejecución: 88-89. Allí aparece Isabel de perfil con su ropa de escritora, se la nerviosa nerviosa porque tiene los ojos cerrados y en la piel de su rostro se ven pequeñas gotas de sudor. A su lado y fundiéndose en la oscuridad se dibuja la silueta del Diablo. Sobresalen sus cuernos y su mentón, y también sus órganos genitales. Esta página nos prepara para lo que creemos que será el encuentro de Isabel con el mal y lo que sucedió en México. «El Diablo», como bien indica Antonio Risco, va a la cabeza de las cosas que irrumpen en la realidad por lo que «en la literatura propiamente fantástica, sin el menor género de dudas, son más frecuentes las apariciones maléficas que las benéficas» (1987: 190).

En esta historia personal de Isabel también funciona muy bien «el contraste de dos espacios opuestos en sus leyes» que indicaba Antonio Risco al explicar el surgimiento de lo fantástico como «oposición entre dos ámbitos o planos existenciales, uno supuestamente normal, que ha de aproximarse suficientemente a la cotidianeidad del lector, y el otro anormal, prodigioso, maravilloso» (1987: 153).

La siguiente viñeta de la historia de Isabel tras es página inquietante con el diablo, es un picado de los pies de Isabel siguiendo lo que parecen las extrañas huellas gigantes de un gallo. Los lectores del cuadernillo 29 de Love and Rockets de 1989, asociarán estas huellas de gallo gigantes de la viñeta con la cabeza de un gallo a todo color que aparece llenando la portada. Este guiño se perderá en las ediciones compilatorias. La viñeta que continúa es un contrapicado en el que vemos a la Isabel escritora con aspecto descuidado cargando una maleta y con un abrigo amplio. La escritora está en un pueblo de Mé- 
xico y un hombre la para por la calle, y le pide que le ayude con su hijo pequeño Beto que no quiere comer. Isabel que tiene varios hermanos y ha cuidado niños, entre ellos a Maggie, se gana el afecto del pequeño Beto y es contratada por el padre del muchacho para que lo cuide. Isabel se queda en esa casa cocinando y cuidando del niño. En esa temporada que hace de niñera y ama de casa parece que la escritora recupera la calma. Cocina, lava la ropa, pasea por el mercado con el niño y empieza a llevar una vida muy cordial con el niño y su padre. Poco a poco el padre de Beto, al que su mujer abandonó, va desarrollando una relación cada vez más cordial e íntima con Isabel. Sin embargo esa armonía un día se rompe. Una tarde al volver de su paseo con Beto, una vieja siniestra sentada en una esquina y abrazada a un gallo le dice a Isabel que sabe quién es ella. Este encuentro desencadena un nuevo comportamiento en Isabel que se apresura a compartir con el padre de Beto su diario íntimo. El hombre se sorprende y no entiende la razón por la que Isabel le ha dado a leer sus pensamientos y confesiones personales. El hombre le responde que no está aquí para juzgarla y que la amaría aunque fuera el diablo mismo. Parece que el amor incondicional del hombre le da tranquilidad a Isabel que pasea por las calles sin angustiarse con la presencia de la vieja. Pero sus días serenos se terminan. Cerca del río sobre el puente Isabel se encuentra a un hombre rubio vestido de negro que crece delante de ella como una sombra maléfica. El encuentro con este ente extranatural desencadena una huida de Isabel. La escritora recoge sus cosas y se despide silenciosa del hombre que está dormido y no escucha las dolorosas palabras de Isabel: «Forgive me, darling, but he's found me and I can't risk getting you and Beto involved...» (1989: 24).

Los lectores seremos los únicos testigos del amor de Isabel por esa familia y su desesperada huida por el bosque. Isabel llegará a otro pueblo, alquilará un piso y se quedará encerrada tratando de esconderse. En el piso comenzarán a suceder fenómenos parapsicológicos que desembocan en lo sobrenatural diabólico. El crucifijo de la pared cae y queda bocabajo fijado al suelo. Izzy y los lectores entendemos que esa es la señal que indica la presencia de lo sobrenatural malévolo en la habitación. Izzy se lamenta de su suerte temblorosa y se confiesa en voz alta: «Oh, God. Why me? / I'm not the first person that ever got a divorce...or an abortion...or an attempted suicide...» (1989: 24). De la grieta de la pared junto al crucifijo bocabajo sale una voz que dialoga con Izzy y le dice que no son sus pecados, sino su sentimiento de culpa lo que le permite llegar hasta ella. El miedo y el sentimiento de culpa de Izzy hacen poderoso a ese ser diabólico que dialoga con ella desde la grieta. 
Ella lo reconoce como el señor Satánico y la voz se resiste a ser identificada por un género: «Mister? What makes you think I'm a he?» $(1989,24)$. Izzy asocia esa voz a la voz de su propio padre al que detesta. Ella no quiere regresar a la casa familiar mientras su padre siga viviendo allí, y eso es lo que le expresa a su madre en una carta.

María del Carmen Tacconi de Gómez explica como lo «parapsicológico corresponde a fenómenos que todavía se mantienen en el ámbito de lo misterioso: la percepción extrasensorial, los sueños premonitorios, la levitación, la telequinesis, etc.» (1995: 40). Izzy vive asolada por percepciones extrasensoriales que le hacen tener premoniciones ominosas y miedos incontrolables. Sus problemas personales, su pasado, el enfrentamiento con su padre, sus sentimientos de culpa y las frustraciones que acumula ayudan a fabricar ese diablo invisible que la acosa y se convierte en una voz que sale de las grietas de la pared. Confirmando como bien indica María del Carmen Tacconi de Gómez que en «el ámbito de lo fantástico-parapsicológico se manifiestan mucho más abiertamente las miserias y las mezquindades del ser humano» (1995: 45). Izzy ante esa voz que la interpela vuelca sus pensamientos y se quita la máscara dialogando con lo diabólico desde el ámbito de la intimidad.

Llegará un momento en el que Izzy se sentirá con fuerzas para enfrentarse a ese ser satánico que la persigue. Quiere verlo y romper de este modo con el espanto que siente. Las siguientes viñetas mudas se centrarán en el personaje de Izzy y la forma que tiene de enfrentarse al diablo. Se reirá sola en una silla, sentirá un terrible dolor y tendrá vómitos llenos de lagartijas. Emprenderá una nueva huida marcada por la fatalidad donde sombras masculinas alargadas la seguirán de cerca por un camino desolado en el que la escritora se arrastra. Veremos un primer plano de la media cara del diablo con los dientes afilados. A continuación, dos viñetas de dos niñas jugando a la primera comunión en una habitación con una cómoda, luego, una viñeta de plano detalle del primer cajón de la cómoda abierta con la cabeza de un exvoto de cristo ensangrentado, y por fin un plano medio de la protagonista despertándose súbitamente. Izzy está rodeada por dos mujeres, una de ellas la vieja que llevaba un gallo en los brazos y que tanto la asustó al reconocerla tiempo atrás en la calle cuando paseaba con el pequeño Beto. Las viñetas muestran a Izzy de parto, y podemos intuir que están naciendo cosas monstruosas, porque aparecen dibujadas colas de diablos y lagartijas junto a un pequeño y extraño cuerpo de diablo. Del gesto de dolor de Izzy en un primer plano que cierra el episodio del parto monstruoso pasamos a una secuencia de viñetas serenas.

Una viñeta en primer plano nos muestra la silueta de un gallo con una 
lagartija en el pico, otra viñeta en primer plano se enfocará en el rostro tranquilo de Izzy. El paso del tiempo lo marcará la representación del pelo largo de Izzy, que por fin será capaz de salir de la cama, y volverá con el pequeño Beto y su padre, esa familia que en cierta forma la adoptó en México. Sin embargo la pesadilla no termina y un día, cuando descubra que su padre ha muerto, emprenderá de nuevo viaje y regresará a los Estados Unidos. El rastro de lo diabólico, de esa culpa que la persigue, ahora se habrá convertido en moscas en el techo. Izzy trata de explicárselo al padre de Beto, que tiene que aceptar que la protagonista les va a volver a dejar: «He also refuses to give me up. Says he'll be waiting for me in the States. / 'I may turn up as flies on your ceiling', he said...» (1989: 31).

Las moscas serán el rastro que recuerde los episodios de culpa de Izzy y sus desencuentros con el diablo. Funcionan en cierto modo como diminutos seres fantásticos malignos difuminados por la realidad contemporánea.

La cronología vital de Izzy está muy bien definida a lo largo de toda la serie y Marc Sobel y Kristy Valenti lo recogen con detalle en su Companion. Izzy nace en 1958, un año antes que el propio Jaime Hernández. En 1966 hará de niñera de Maggie. En 1979 presenta a Maggie y a Hopey. En ese mismo año tiene su matrimonio fallido con Jack Reubens su profesor de inglés de la universidad. Será un año después, en 1980, cuando escapa a México torturada por la culpa de un aborto y tiene los encuentros con el diablo. En 1985 es cuando su hermano Speedy se suicida después de una oleada de violentos enfrentamientos entre bandas. Su querido hermano, en los código católicos que marcan su formación, también comete un pecado mortal y esto suma ansiedades a su obsesiva personalidad.

Lo fantástico se va tejiendo dentro de la personalidad íntima de Izzy y la proyecta como un ser torturado por la intuición y el presentimiento de verse acosada por el demonio. Esa presencia la irá demacrando a lo largo de los años haciendo de ella un ser esperpéntico y fantasmal. Sin embargo, pese a la dura carga del mal acompañándola, Izzy logrará construir su carrera como escritora y en 1998 aparece su libro The Secrets of Life and Death. Pero su fragilidad emocional se manifiesta y la escritora no soporta tener que hacer presentaciones en público. Ese pánico escénico se convierte en una respuesta física que la vuelve a llevar al espacio de la ficción. Izzy crecerá de forma desmesurada como expresión de sus miedos interiores.

En el libro Ghost of Hoppers (2005), que recogía parte de los cuadernillos de la segunda época de Love and Rockets publicados entre 2001 y 2005, Izzy vuelve a ser una de las protagonistas que trae lo fantástico a la trama realista. 
En este volumen estamos en el año 2001 y Maggie aparece como una mujer de 36 años que trabaja de encargada de los apartamentos Capri en el Valle de San Fernando en California. La rutina de Maggie se complica con la llegada de Izzy, su amiga escritora, que como bien le explica a Hopey es «the incredible shrinking and growing at the same time woman» (2005: 4). Este comentario de Maggie alude a las metamorfosis de su amiga Izzy que están ligadas a sus neurosis y miedos como escritora, y cómo esa experiencia de proyectarse en público, le afecta físicamente. La noche de Izzy en el apartamento de Maggie estará llena de humor e inquietante desconcierto. Izzy sigue siendo esa mujer fantasmal a la que acompaña lo tenebroso. Maggie no podrá resistir la tentación de medir a su amiga escritora con un metro, mientras duerme, para ver si efectivamente crece o se reduce. Esta vez las ansiedades de la escritora le llevarán a tener un cuadro sonámbulo con gritos aterradores que harán que Maggie pase una noche espantosa al no ser capaz de despertarla. Pero esta visita no alude solo al presente, sino que se mezcla con recuerdos inquietantes del pasado cuando Izzy cuidaba de la pequeña Maggie. Una página autoconclusiva de seis viñetas titulada «Maggie» narrará el momento en el que la niña Maggie ve la sombra de un perro que nos recuerda a uno de los perros cancerberos incorporándose dentro de la casa de la señora Galindo (2005: 30). Su amiga Izzy la encuentra y le dice que no debe estar allí, pero Maggie quiere explicarle que ha visto un perro, pero eso es imposible porque como le explica Izzy «Mrs Galindo doesn't have no doggie, mija» (2005: 30). En 1985, la señora Galindo, le dejará en herencia esa casa donde la niña Maggie veía sombras de perros a su amiga Izzy. En el imaginario popular la señora Galindo es la viuda del señor Sal que le deja a Izzy la casa embrujada de Hoppers. Jaime Hernández que quiere recordarnos ese detalle que flashbacks, también juega con los pequeños elementos paranormales recurrentes que asolan a Izzy. El comportamiento excéntrico de Izzy durante su visita a Maggie tendrá un momento de inflexión cuando se cae a la piscina vacía de los apartamentos Capri y está llena de moscas. En ese instante Izzy es consciente de que tiene que regresar a su casa: «I do believe I'm quite ready to go home now» (2005: 41).

El regreso de Izzy a Hoppers será un episodio impregnado de misterio. Maggie llevará a Izzy en su coche al anochecer de vuelta a su casa, la casa heredada de la señora Galindo. En ese viaje las dos amigas discutirán sobre el recuerdo del perro que dice Maggie que vio en esa casa de la señora Galindo. Maggie se vuelve a crispar con su amiga Izzy y trata de romper con su dinámica alienante de negatividad. Maggie negará la existencia de los perros malignos o las moscas: «I'm taking you home, dropping you off in front of your 
house and then I'm leaving, OK? No devil dogs, no flies on the ceilings or in the swimming pools! Got that?» (2005: 43). La trama sin embargo se complicará cuando en una visita familiar que Maggie hará a su hermana Esther y a su madre, las tres recuerden anécdotas sobre la vieja casa de la señora Galindo que Izzy heredó. Esther aludirá a anécdotas concretas: «Remember Perla? Mom used to tell us a witch's curse crippled Mrs.Galindo and that witches lived in the tree in front of her house!» $(2005,90)$. Esther y Maggie niñas creían la historia de la madre que les había contado que una maldición había caído sobre la señora Galindo y que las brujas vivían en el árbol en frente de su casa. La madre alude al recuerdo de todas aquellas cosas que les contaba sobre brujas, fantasmas y el diablo. Las anécdotas sobre los seres fantásticos que fabricaban los adultos para asustarlas cuando eran niña marcan la conversación, y llenan a Maggie de tristeza. Su hermana Esther es muy precisa con los detalles: «Carmen, my friend in third grade said he didn't come to her uncle as a black dog but as a tiny baby saying "I am the devil" over and over again» (2005: 90). Todos esos recuerdos harán que Maggie a su regreso por la noche, decida pasar por la casa de Izzy y se baje a mirar esa casa embrujada que ahora está pintada de negro. Sin embargo la trama da otro giro fantástico cuando Maggie descubra que un niño con pinta de diablo rodeado de perros ha encendido una mecha de líquido inflamable que va directamente a incendiar la casa de Izzy. No encontrarán a Izzy entre los escombros y Maggie se tendrá que enfrentar a una cascada de recuerdos donde demonios, monstruos, perros y fantasmas acompañarán a la memoria de su amiga escritora ahora desaparecida. Con la desaparición de Izzy, tal vez provocada por ella misma y sus propios demonios, parece que Jaime Hernández quiere acotar el imaginario fantástico que rodea la realidad de sus personajes. El autor todavía no sabe qué pasó exactamente con Izzy y lo que implica esta extraña desaparición. Tendremos que esperar a que aparezcan nuevos episodios que redefinan a este personaje tan carismático que ha marcado el diálogo de lo fantástico y lo literario en este cómic.

\section{BibliografíA}

Borges, Jorge Luis, Silvina Ocampo y Adolfo Bioy Casares (1977): Antología de la literatura fantástica, Edhasa-Sudamericana, Barcelona.

Bravo, Victor (1987): Los poderes de la ficción, Monte Ávila Editores, Caracas.

CAmpra, Rosalba (2008): Territorios de la ficción. Lo fantástico, Editorial Renacimiento, Sevilla. 
CARILla, Emilio (1968): El cuento fantástico, Editorial Nova, Buenos Aires.

FARIÑA, María Jesús, y Dolores Troncoso (eds.) (2001): Sobre literatura fantástica: Homenaje ó profesor Antón Risco, Universidad de Vigo, Vigo.

Grotн, Gary (1989): «Entrevista a Los Hermanos Hernández. The Comics Journal enero 1989», en Marc Sobel y Kristy Valenti, The Love and Rockets Companion, Fantagraphics Books, Seattle, pp. 11-79.

HaHn, Oscar (1998): Fundadores del cuento fantástico hispanoamericano, Editorial Andrés Bello, Santiago.

Hernandez, Gilbert, y Jaime Hernandez (1983): Love and Rockets, núm. 2, Fantagraphics Books, Seattle.

(1989): Love and Rockets, núm. 29, Fantagraphics Books, Seattle.

(2003): Flies on the Ceiling, Vol 9 A Love and Rocket Collection, Fantagraphics Books, Seattle.

Hernandez, Jaime (2004): LOCAS. The Maggie and Hopey Stories, A Love and Rockets Book, Fantagraphics Books, Seattle.

(2005): Ghost of Hoppers, Fantagraphics Books, Seattle.

(2007): Maggie and the Mechanic, A Love and Rockets Book, Fantagraphics Books, Seattle.

Herrero Cecilia, Juan (2000): Estética y pragmática del relato fantástico, Ediciones de la Universidad de Castilla-La Mancha, Cuenca.

Honores, Elton (coord.) (2011): Lo fantástico en Hispanoamérica, Cuerpo de la metáfora editores, Lima.

JacKson, Rosemary (1981): Fantasy. The Literature of Subversion, Routledge, Londres y Nueva York.

Merino, José María (2004): Ficción continua, Seix Barral, Barcelona. (2007): «Los límites de la ficción», \#2 Jabberwock. Anuario de Ensayo Fantástico, Bibliópolis/antológica, Madrid, pp. 37-49.

Morales, Ana María, José Miguel Sardiñas y Luz Elena Zamudio (eds.) (2003): Lo fantástico y sus fronteras, II Coloquio Internacional de Literatura Fantástica. Benemérita Universidad Autónoma de Puebla, Puebla.

Risco, Antonio (1987): Literatura fantástica de lengua española, Taurus, Madrid.

RoyAl, Derek Parker (2013): «The Worlds of the Hernandez Brothers», Image Text: Interdisciplinary Comics Studies. 7. 1, Department of English, University of Florida, Web, 19 pp.

Sobel, Marc, y Kristy Valenti (2013): The Love and Rockets Companion, Fantagraphics Books, Seattle.

TacConi de Gómez, María del Carmen (1995): Categorías de lo fantástico y constituyentes del mito, Universidad de Tucumán, Tucumán.

Todorov, Tzvetan (1981): Introducción a la literatura fantástica, Premiá editora, México.

Trabado Cabado, José Manuel (2014): «Palomar: la frontera de lo insólito en el cómic de Beto Hernández», en Javier Ordiz (ed.), Estrategias y figuraciones de lo insólito en la narrativa mexicana (siglos XIX-XxI), Peter Lang, Nueva York, pp. 197-217. 
